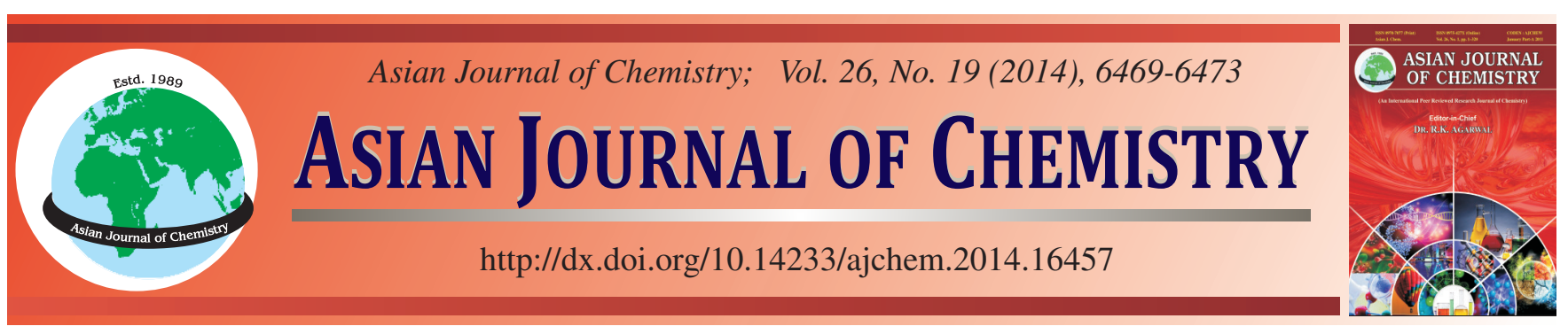

\title{
Polyoxymethylene Dimethyl Ethers from Methylal and Trioxane over Modified Cation-Exchange Resin
}

\author{
JiAnQiang Zhang, Bin TAng, Dingye FAng* and Dianhua Liu*
}

State Key Laboratory of Chemical Engineering, East China University of Science and Technology, Shanghai 200237, P.R. China

*Corresponding authors: Tel: +86 21 64252151; E-mail: dyfang@ecust.edu.cn; dhliu@ecust.edu.cn

Received: 1 October 2013;

Accepted: 24 December 2013;

Published online: 16 September 2014;

AJC-15942

\begin{abstract}
Polyoxymethylene dimethyl ethers can increase cetane number and improve combustion efficiency when added to diesel fuel. Although intermittent reaction of polyoxymethylene dimethyl ethers synthesized from methylal and trioxane in a batch reactor has been known, the continuous reaction process for the synthesis of polyoxymethylene dimethyl ethers is still been pursued. The present work gives an overview of continuous process for the synthesis of polyoxymethylene dimethyl ethers from methylal and trioxane. The acidic cationexchange resin modified by para-toluenesulfonic acid was used as catalyst for this process. The prepared catalysts were characterized by using several techniques such as BET, $\mathrm{NH}_{3}$-TPD and SEM. The analytical results of $\mathrm{NH}_{3}$-TPD reveal that the modified catalyst exhibited stronger acidity and less acidic sites than untreated catalyst. A relationship between catalytic performance in polyoxymethylene dimethyl ethers formation and the acid properties of catalyst is found. Their catalytic performance was assessed in a fixed-bed micro-activity test unit in a broad experiment range (temperature, residence time, pressure). The modified catalyst of acidic cation-exchange resin with 20 wt. \% para-toluenesulfonic loading showed the highest performance. The modified catalyst presented significantly higher activity at 343 $\mathrm{K}$. The methylal conversion was increased from 38.76 to $48.84 \%$ with the increased of pressure from 0.5 to $2.0 \mathrm{MPa}$. Residence time analysis showed that the modified catalyst is stable at $20 \mathrm{~min}$ reaction time. The appropriate reaction conditions are temperature $343 \mathrm{~K}$, pressure $2 \mathrm{MPa}$ and residence time $20 \mathrm{~min}$.
\end{abstract}

Keywords: Polyoxymethylene dimethyl ethers, Continuous process, Catalyst, Methylal, Trioxane.

\section{INTRODUCTION}

Millions of buses and trucks exhaust a huge amount of $\mathrm{NO}_{\mathrm{x}}$ and particulates, therefore green fuel are seriously desired. Some oxygenated compounds, such as methanol, dimethyl ether, methylal and polyoxymethylene dimethyl ethers, are known to reduce soot formation and improve fuel efficiency during the combustion when added to diesel fuel ${ }^{1}$. Because of lower cetane number (methanol) and higher vapor pressure (dimethyl ether and methylal), the engines infrastructure have to be changed when methanol, dimethyl ether ${ }^{2}$ or methylal ${ }^{3}$ was used as additive of diesel fuel ${ }^{4}$. Comparing low molecular weight chemicals ${ }^{5-9}$, polyoxymethylene dimethyl ethers have higher cetane number and lower vapor pressure. polyoxymethylene dimethyl ethers which can improve combustion efficiency are suitable components for blending into diesel fuel. As important chemical materials, polyoxymethylene dimethyl ethers have attracted much more attention in recent years to be used as a green energy resource.

With the structure represent by the type formula $\mathrm{CH}_{3} \mathrm{O}-$ $\left(\mathrm{CH}_{2} \mathrm{O}\right)_{\mathrm{n}}-\mathrm{CH}_{3}$ (abbreviated to $\mathrm{PODE}_{\mathrm{n}}$ ), polyoxymethylene dimethyl ethers are acetals closely related to methylal which may be regarded as the parent member of the group in which the type formula $n$ equals $1^{10}$. Especially, $\mathrm{PODE}_{3 \leq n \leq 8}$ exhibits high oxygen content, moderate boiling points ${ }^{11}$ and excellent miscibility with diesel fuel. Also, its average cetane number is above 76. polyoxymethylene dimethyl ethers are the typical green energy and has the similar physical and chemical properties with the diesel fuel ${ }^{12}$. So it can be blend to diesel fuel and used without changing the engine's infrastructure ${ }^{13,14}$. It is degradable and could replace a range of environmentdamaging sulfide and aromatic compound which will result in a much cleaner environment.

Retrieving literatures, we find that literatures rarely reported on polyoxymethylene dimethyl ethers production from methylal and trioxane. In the past century, polyoxymethylene dimethyl ethers are prepared in laboratory scale by heating polyoxymethylene glycols or para-formaldehyde with methanol in the presence of a trace of sulfuric acid or hydrochloric acid in a sealed tube for $15 \mathrm{~h}$ at $423 \mathrm{~K}$. The synthesis of polyoxymethylene dimethyl ethers is an acid catalyzed reaction ${ }^{15}$. With the presence of water and acid, polyoxymethylene dimethyl ethers are easily hydrolyzed to hemiacetals, methanol and formaldehyde. Therefore, methylal and trioxane is the most 
suitable raw material for polyoxymethylene dimethyl ethers formation in which water-free environment was realized. Burger et al. ${ }^{10}$ synthesized polyoxymethylene dimethyl ethers from methylal and trioxane in a stirred batch reactor. Because of trioxane is a chemically stable solid at ambient conditions, the reaction of polyoxymethylene dimethyl ethers from methylal and trioxane in a previous study was implemented in batch reactor. In order to realize the continuous reaction, several measures were adopted in present work.

With the development of chemical industry, solid acid catalysts have received increasing attention and they have shown promising catalytic performance in dehydration and esterification reactions and so on. Compared with liquid acid catalysts, solid acid catalysts have many advantages such as low pollution, low corrosive, easy to separation, etc. More and more liquid-phase catalytic reactions use solid catalyst to replace liquid catalyst. As solid catalyst, acidic cation-exchange resin ${ }^{16-18}$ shows high performance in acid catalytic reaction. Unlike the conventional catalysts, acidic cation-exchange resin provide the unique feature of shape selectivity because of their repeatable pore structure which may prove to be useful to the reaction under consideration. Because of the large pore structure, some special modifier can be used for forming specialized structures. It can be used for some reaction to improve the aim product selectivity.

The objective of this paper is to achieve continuous process and evaluate the performance of modified acidic cationexchange resin catalysts for reaction of methylal and trioxane to polyoxymethylene dimethyl ethers. The effects of various parameters such as temperature, pressure and residence time are determined. Ultimately, a suitable reaction condition is proposed.

\section{EXPERIMENTAL}

The materials are sodium type of acid cation exchange resin (95\% Sino Polymer Co CHN), para-toluenesulfonic acid $\left(\mathrm{C}_{7} \mathrm{H}_{8} \mathrm{O}_{3} \mathrm{~S} 99 \%\right.$ Sinopharm Group Co $\left.\mathrm{CHN}\right)$, ethanol $\left(\mathrm{C}_{2} \mathrm{H}_{6} \mathrm{O}\right.$ $99 \%$ Sinopharm Group Co CHN), hydrochloric acid ( $\mathrm{HCl} 37$ \% Sinopharm Group Co CHN), sodium hydroxide ( $\mathrm{NaOH} 99$ $\%$ Sinopharm Group Co $\mathrm{CHN})$, sulfuric acid $\left(\mathrm{H}_{2} \mathrm{SO}_{4} 98 \%\right.$ Sinopharm Group Co CHN), methanol $\left(\mathrm{CH}_{4} \mathrm{O} 99.9 \%\right.$ Sinopharm Group Co CHN), formaldehyde $\left(\mathrm{CH}_{2} \mathrm{O} 37 \%\right.$ in water Sinopharm Group Co $\mathrm{CHN})$, methylal $\left(\mathrm{C}_{3} \mathrm{H}_{8} \mathrm{O}_{3} 98 \%\right.$ Sinopharm Group Co CHN) and trioxane $\left(\mathrm{C}_{3} \mathrm{H}_{6} \mathrm{O}_{3} 98 \%\right.$ Sinopharm Group Co CHN). The purity of all chemicals (liquid-phase) was verified by gas chromatography.

\section{Catalyst preparation}

Hydrogen type of acid cation exchange resin: Hydrogen type of acid cation exchange resin was obtained by hydrochloric acid exchanging sodium type of acid cation exchange resin. In order to remove the cross linker of sodium type of acid cation exchange resin, it was washed by hydrochloric acid $(6 \% \mathrm{~g} / \mathrm{g})$, sodium hydroxide $(6 \% \mathrm{~g} / \mathrm{g})$, ethanol $\left(\mathrm{C}_{2} \mathrm{H}_{6} \mathrm{O}\right.$ $99 \%)$ in sequence. Then the ion-exchange capacity of the sample was now determined by displacing the entire exchangeable $\mathrm{H}^{+}$ion (hydrochloric acid) with $\mathrm{NaCl}$ solution into a conical flask. In the impregnation process, the washed resin was exchanged with the certain amount of hydrochloric acid solution $(6 \% \mathrm{~g} / \mathrm{g})$ for $10 \mathrm{~h}$. Then the catalyst was dried at 353 $\mathrm{K}$ for $12 \mathrm{~h}$. After that the catalyst hydrogen type of acid cation exchange resin obtained was labeled as HD-S.

para-Toluenesulfonic modified acid cation exchange resin: In the process of preparation of modified catalyst, different quality( $1 \mathrm{~g}, 2 \mathrm{~g}, 3 \mathrm{~g})$ of para-toluenesulfonic acid was dissolved in $20 \mathrm{~mL}$ deionized water respectively at room temperature. The resulting colourless solution contained various amounts of para-toluenesulfonic and their $\mathrm{pH}$ were lower than 1 . The sulfonic acid group concentration varied from 0.3 to $0.9 \mathrm{ml} / \mathrm{L}$. Add these solutions to three flasks and swirl the flasks for about 60s. Then hold flaks at $323 \mathrm{~K}$ and slowly add $10 \mathrm{~g}$ catalyst HD-S while continuously swirling the three flaks. After $4 \mathrm{~h}$ impregnation, the three mixtures were then filtered through $50 \mathrm{~cm}$ fluted filter paper and the impregnated solids were separated from the excess solutions. Then the solid-catalyst was dried at $353 \mathrm{~K}$ for $12 \mathrm{~h}$. This series of catalysts HD-S samples with 0, 10, 20 and 30 wt. \% paratoluenesulfonic loading were named HD-S, HD-S -P10, HDS-P20 and HD-S-P30, respectively.

Catalyst characterization: The pore volume, pore diameter and BET surface area of catalysts were measured by nitrogen adsorption at $77 \mathrm{~K}$ using an ASAP 2020 surface area and porosity analyzer. Prior to the $\mathrm{N}_{2}$ adsorption, the samples were outgassed for $12 \mathrm{~h}$ at $473 \mathrm{~K}$. The specific surface areas were calculated using BET equation.

The catalyst acidity was measured by temperature programmed desorption of ammonia ( $\mathrm{NH}_{3}$-TPD) conducted on Auto Chem II 2920 (Micromeritics, USA) instrument. A sample of $0.14 \mathrm{~g}$ was pretreated in flowing helium at $873 \mathrm{~K}$ for $1 \mathrm{~h}$ and then exposed to $\mathrm{NH}_{3}$ for $0.5 \mathrm{~h}$ at $353 \mathrm{~K}$. After saturation, the sample was purged with helium for $0.5 \mathrm{~h}$ to remove the physisorbed $\mathrm{NH}_{3}$. The TPD measurements were conducted in flowing helium $(30 \mathrm{~mL} / \mathrm{min})$ from $353 \mathrm{~K}$ to $1073 \mathrm{~K}$ at a heating rate of $10 \mathrm{~K} / \mathrm{min}$.

Scanning electron microscopy (SEM) images were obtained with a JEOL JSM-6360LV instrument to determine the textural properties, structure of the capsule catalyst and presence of macroscopic defects.

Catalytic reaction: The reaction was carried out in a tubular reactor (700 $\mathrm{mm}$ long and $12 \mathrm{~mm}$ i.d.) with catalyst (particle diameter: 0.18-0.25 mm), as shown in Fig. 1.

The reaction was performed at 0.5 to $2.0 \mathrm{MPa}$. Temperature was increased at an interval of $20 \mathrm{~K}$ from 323 to $383 \mathrm{~K}$. The raw material of methylal and trioxane flow rate was increased in the range of 0.1-0.5 $\mathrm{mL} / \mathrm{min}$.

Trioxane is solid at room temperature. In the experiment, in order to realize continuous feed, heater band was used for keeping raw material (methylal and trioxane) up to $343 \mathrm{~K}$. At $343 \mathrm{~K}$, the raw material is solution for trioxane dissolving in methylal. Then it can be continuous transferred to the reactor. The feed tank with raw material methylal and trioxane solution was placed in the water bath at constant temperature $343 \mathrm{~K}$. And the transportation equipment used heat pump at $343 \mathrm{~K}$.

Analytical methods: The effluent liquid and gas was analyzed using a gas chromatograph (PE 580) equipped with Elite-wax fused silica capillary column $(30 \mathrm{~m} \times 0.32 \mathrm{~mm} \times$ $0.25 \mu \mathrm{m}$ ). A flame ionization detector (FID) operating at $553 \mathrm{~K}$ was utilized for analyzing liquid product with nitrogen as 


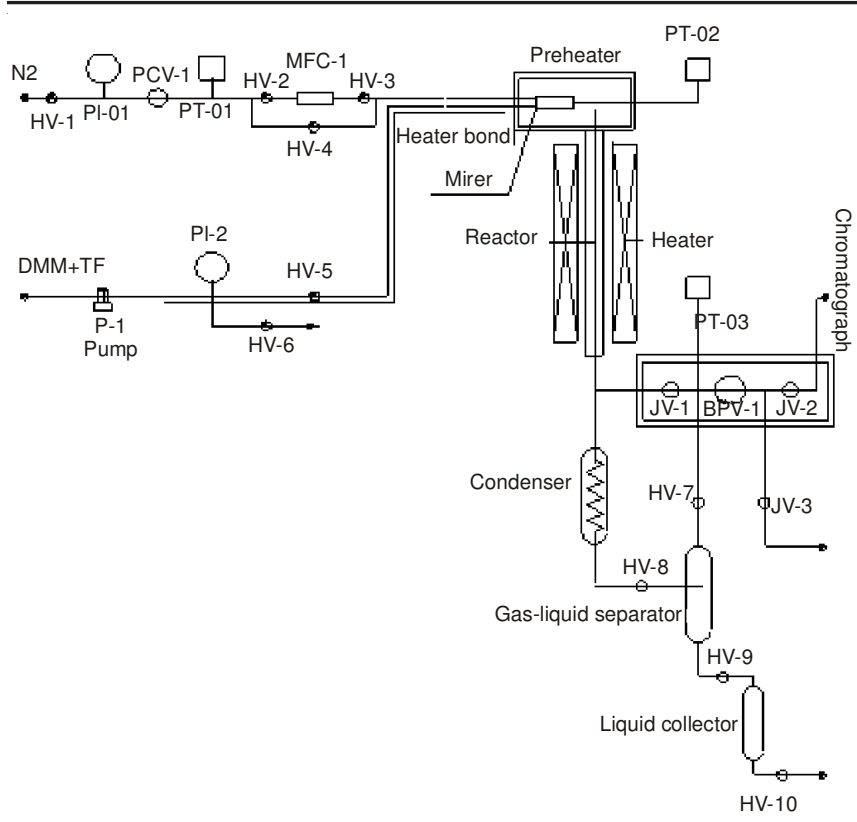

Fig. 1. Reaction system for polyoxymethylene dimethylether formation from methylal and trioxane

carrier gas. Thermal conductivity detector (TCD) operating at $553 \mathrm{~K}$ was utilized for analyzing gaseous product with hydrogen as carrier gas. The column oven temperature was maintained at $318 \mathrm{~K}$ for $3 \mathrm{~min}$, then increased to $373 \mathrm{~K}$ at a rate of $5 \mathrm{~K} / \mathrm{min}$ and held there for $1 \mathrm{~min}$. Finally, the temperature was increased at a rate of $20 \mathrm{~K} / \mathrm{min}$ to $595 \mathrm{~K}$ and kept constant for $3 \mathrm{~min}$. GC samples were taken until the successive reactor composition remained constant over time, at which point the temperature was set to the next desired value and GC sampling resumed. The material balance was found satisfactory. The average absolute percent deviation in this analysis was under $3 \%$.

\section{RESULTS AND DISCUSSION}

The results of the surface area, average pore diameter and pore volume for catalysts HD-S and HD-S-P20 are presented in Table-1.

\begin{tabular}{cccc}
\multicolumn{4}{c}{ TABLE-1 } \\
\multicolumn{4}{c}{ PHYSICOCHEMICAL PROPERTY OF } \\
& THE CATALYSTS HD-S AND HD-S -P20 \\
\hline Catalysts & BET area $\mathrm{m}^{2} / \mathrm{g}$ & $\begin{array}{c}\text { Average pore } \\
\text { size }(\mathrm{nm})\end{array}$ & $\begin{array}{c}\text { Pore volume } \\
\left(\mathrm{cm}^{3} / \mathrm{g}\right)\end{array}$ \\
\hline HD-S & & 33.67 & 0.22 \\
HD-S-P20 & 25.34 & 30.38 & 0.06 \\
\hline
\end{tabular}

The catalyst HD-S-P20 with 20 wt. \% para-toluenesulfonic modification exhibits the lower BET surface area and pore volume. This is due to the catalyst's surface properties changes as the modification of para-toluenesulfonic acid. With evidence of small difference of average pore size between HD-S and HD-S -P20, the para-toluenesulfonic is loaded to the pore internal surface of catalyst. The modifier within the pore reduces the surface area and pore volume of the catalyst that leads to the decrease of weaker-acid amount. The modifier with strongly acidic sulfonic acid group enhances the acid strength of modified catalyst.
The surface acidic properties of the catalyst HD-S and HD-S-P20 were characterized by $\mathrm{NH}_{3}$-TPD. The results are shown in Fig. 2. It indicates that the only one peak was observed for each catalyst. The two peaks appeared in $\mathrm{NH}_{3}$-TPD profile at temperature above $823 \mathrm{~K}$, indicating that there are only super acid sites over the two catalysts. For para-toluenesulfonic acid modified catalyst, the acid peak is shifted to higher temperatures. It means that the acid strength of HD-S was enhanced by the para-toluenesulfonic acid modification. The lower peak height means that the number of the acid sites was decreased by the modification. The change of catalyst acidity could be attributed to the introduction of para-toluenesulfonic acid into the pore of resin. It is highly agreement with the results of the BET test. With the impregnation of para-toluenesulfonic acid, the catalyst shows that the decrease of weaker-acid amount and the enhancement of acid strength.

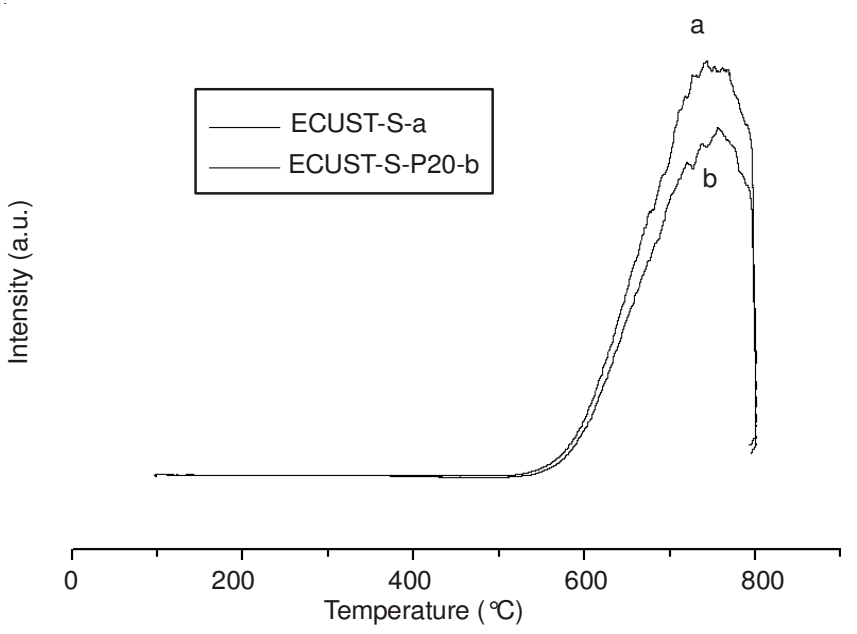

Fig. 2. $\mathrm{NH}_{3}$-TPD patterns of catalyst HD-S and HD-S-P20

Fig. 3 exhibits the scanning electron microscopy of the catalyst HD-S and HD-S-P20. It shows small changes in the morphology of the two catalysts. Such a gradual growth of typical quasi-spherical particles was observed in the surface of HD-S-P20. With the introduction of para-toluenesulfonic acid, smaller and neater particles are observed. This confirms that the morphological properties changed after the addition of para-toluenesulfonic acid.
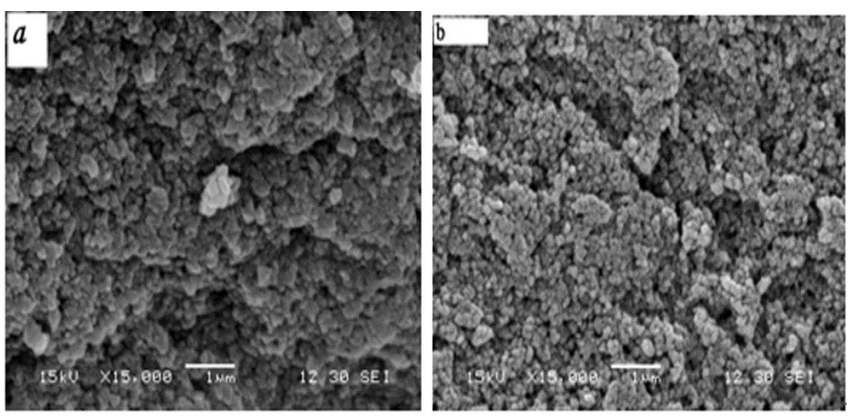

Fig. 3. SEM image of catalyst HD-S (a) and HD-S-P20 (b)

Effect of para-toluenesulfonic acid: The pristine and para-toluenesulfonic modified acid cation exchange resin (HD-S, HD-S-P10, HD-S-P20 and HD-S -P30) were evaluated 
under the same reaction conditions. The results are shown in Fig. 4. Reaction conditions: pressure, $1 \mathrm{MPa}$; temperature, 343 $\mathrm{K}$; Flow rate, $0.1 \mathrm{~mL} / \mathrm{min}$; catalyst, $0.5 \mathrm{~g}$.

As shown in Fig. 4, the selectivity of polyoxymethylene dimethyl ethers increased with the increase of para-toluenesulfonic acid amounts. The mainly by-product of this reaction is methanol, formaldehyde and methoxy methanol. The significant improvement of polyoxymethylene dimethyl ethers selectivity at the low temperature is attributed to the decrease of acid sites that lead to a lower molecular weight by-product formation. The hydrolysis reaction of methylal produced to methoxy methanol with acid catalyst and the reaction of methoxy methanol further reacted to methanol and formaldehyde were both inhibited. The decrease of by-product results polyoxymethylene dimethyl ethers selectivity increased. When the para-toluenesulfonic acid loading amounts was more than $20 \%$, polyoxymethylene dimethyl ethers selectivity was low changed. Because of the pore of resin catalyst was fully occupied with modifier, the acids sites were not decrease with the increase of loading amounts. Moreover the selectivity of $\mathrm{PODE}_{3-8}$ was increased slightly and the conversion of methylal remained constant. Taking into account the reaction of methylal and trioxane to polyoxymethylene dimethyl ethers and the catalytic performance, the catalyst HD-S-P20 is recommended for the polyoxymethylene dimethyl ethers formation from methylal and trioxane.

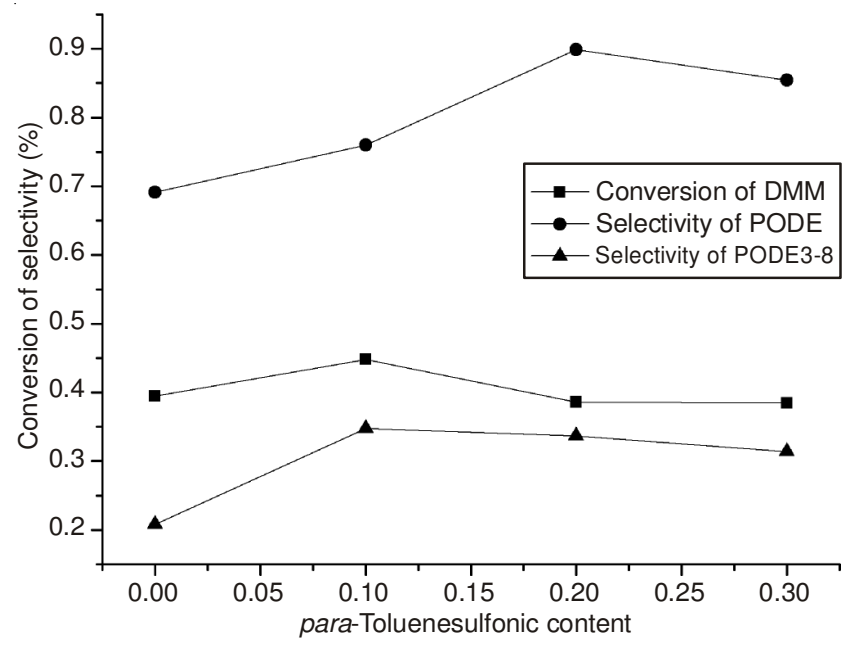

Fig. 4. Effect of para-toluenesulfonic acid amounts on polyoxymethylene dimethyl ethers formation from methylal and trioxane with modified catalysts. The accuracy of methylal conversion can be estimated as \pm 0.23 (95\% confidence interval)

Effect of temperature: Among the various modified catalysts, HD-S-P20 catalyst showed higher polyoxymethylene dimethyl ethers selectivity in the reaction and its performance test was carried out as a function of temperature. The results are shown in Fig. 5.

Polyoxymethylene dimethyl ethers can be reformed from methylal and trioxane in endothermic reactions. Reactivity test was carried out at an interval of $20 \mathrm{~K}$ from $323 \mathrm{~K}$ to $383 \mathrm{~K}$ at $1 \mathrm{MPa}$. The results show that polyoxymethylene dimethyl ethers synthesis reaction exhibited a maximum with temperature. This could be a compromised result of the change in

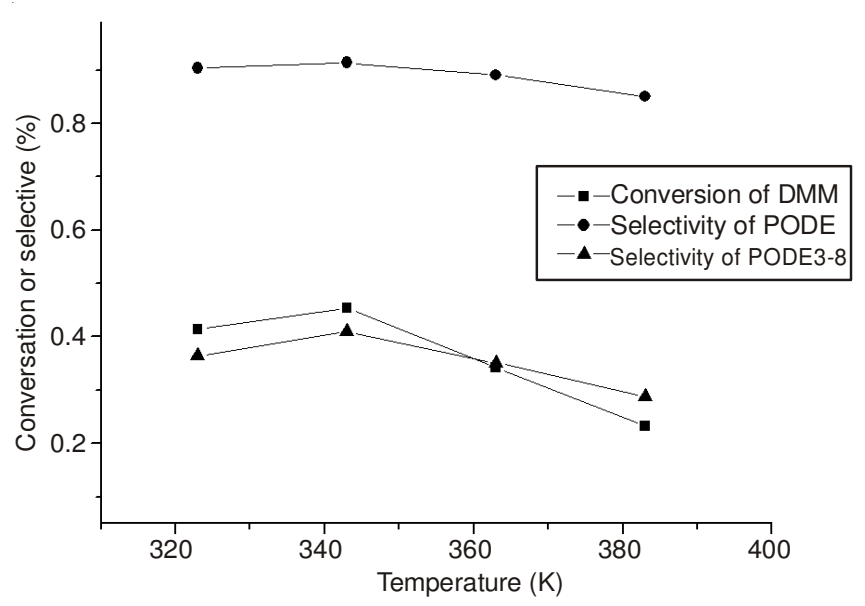

Fig. 5. Effect of temperature on polyoxymethylene dimethyl ethers formation from methylal and trioxane with modified catalyst HD$\mathrm{S}-\mathrm{P} 20$. The accuracy of methylal conversion can be estimated as \pm 0.23 (95\% confidence interval)

rate and equilibrium of the reaction with temperature as the former increases and the latter decreases with temperature. It is observed that the temperature has little effect on the selectivity of polyoxymethylene dimethyl ethers. But the selectivity of $\mathrm{PODE}_{3-8}$ and the conversion of methylal have optimal activity at $343 \mathrm{~K}$. Fig. 5 shows that the catalyst exhibited higher performance on polyoxymethylene dimethyl ethers formation from methylal and trioxane at $343 \mathrm{~K}$.

Effect of pressure: Effect of pressure on reactivity was investigated using catalyst HD-S -P20. The pressure was increased in the range of 0.5-2 MPa. Temperature was $343 \mathrm{~K}$ and catalyst was placed $0.5 \mathrm{~g}$ in fixed-bed micro-activity reactor. The results of catalytic performance are presented in Fig. 6.

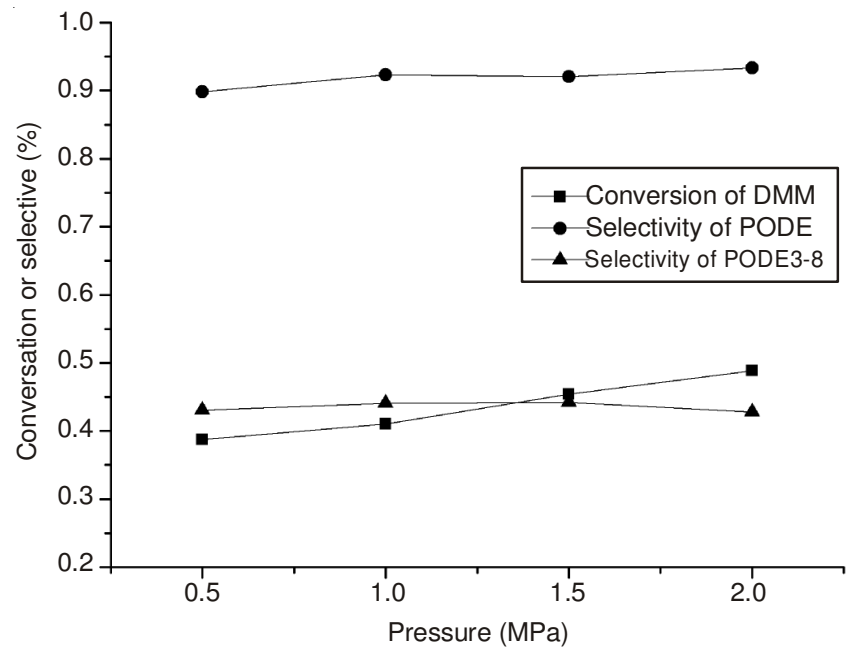

Fig. 6. Effect of pressure on polyoxymethylene dimethyl ethers formation from methylal and trioxane with modified catalyst HD-S-P20. The accuracy of methylal conversion can be estimated as \pm 0.23 (95\% confidence interval)

Fig. 6 shows that the methylal conversion was increased from 38.76 to $48.84 \%$ with the increased of pressure from $0.5 \mathrm{MPa}$ to $2 \mathrm{MPa}$. The increase pressure promotes the small molecule polymerization reaction and polyoxymethylene 
dimethyl ethers formation. Moreover the selectivity of polyoxymethylene dimethyl ethers and $\mathrm{PODE}_{3-8}$ remained constant at different pressure. Indeed, this is a logical trend, since this reaction is reduced molecules reaction; the reaction rate is enhanced by the increasing pressure without negative effect on the shift conversion. Nevertheless, higher pressures than $2 \mathrm{MPa}$ might not the operationally desirable. As such, it may be concluded that pressure of about $2 \mathrm{MPa}$ is suitable for this reaction.

Effect of residence time: Residence time on polyoxymethylene dimethyl ethers formation was investigated using modified catalyst HD-S-P20. The influences of residence time on polyoxymethylene dimethyl ethers formation from methylal and trioxane are presented in Fig. 7. Temperature was $343 \mathrm{~K}$, pressure was $1 \mathrm{MPa}$ and catalyst HD-S-P20 was placed $0.5 \mathrm{~g}$. The residence time was increased in the range of 10-25 min. The methylal conversion was increased from 33.74 to $40.85 \%$ and the selectivity of $\mathrm{PODE}_{3-8}$ was increased from $32.06 \%$ to $37.65 \%$ with the increased of residence time from $10 \mathrm{~min}$ to $20 \mathrm{~min}$. However, further increasing residence time the methylal conversion and selectivity of $\mathrm{PODE}_{3-8}$ remained unchanged. Residence time has little effect on the selectivity of polyoxymethylene dimethyl ethers. It can be concluded that the modified catalyst is stable at 20 min reaction time.

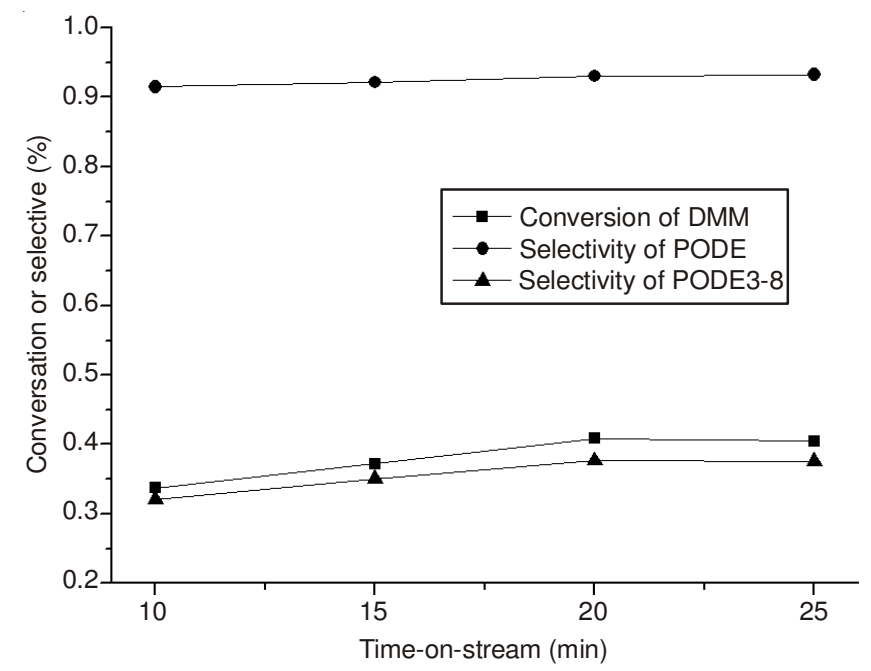

Fig. 7. Effect of residence time on polyoxymethylene dimethyl ethers formation from methylal and trioxane with modified catalyst HD$\mathrm{S}-\mathrm{P} 20$. The accuracy of methylal conversion can be estimated as \pm 0.23 (95\% confidence interval)

Less reaction time means lower conversion of methylal. The reactions of polyoxymethylene dimethyl ethers from methylal and trioxane are series of cascade reactions. $\mathrm{PODE}_{\mathrm{n}+1}$ synthesize from $\mathrm{PODE}_{\mathrm{n}}$ and one third of trioxane. Short reaction time is not conducive to the formation of long chain molecules. Therefore, the selectivity of $\mathrm{PODE}_{3-8}$ was increased with the increase of residence time.

\section{Conclusion}

The present work gives an overview of continuous process technology for the synthesis of polyoxymethylene dimethyl ethers from methylal and trioxane. A series of solid acid catalysts were prepared by impregnation method. Hydrogen type of acid cation exchange resin and para-toluenesulfonic acid modified resin were used for polyoxymethylene dimethyl ethers formation from methylal and trioxane. The selectivity of polyoxymethylene dimethyl ethers was enhanced by paratoluenesulfonic modification. The analytical results show that the acid strength was enhanced and the number of the acid sites was decreased after modification. The catalyst containing 20 wt. \% para-toluenesulfonic exhibits better reactivity and selectivity. Thus, the catalyst HD-S-P20 is recommended for the reaction.

At $343 \mathrm{~K}$, the catalyst exhibited higher performance on polyoxymethylene dimethyl ethers formation from methylal and trioxane. The increase pressure promotes the small molecule polymerization reaction and pressure of about $2 \mathrm{MPa}$ is suitable for this reaction. The methylal conversion was increased from 33.74 to $40.85 \%$ and the selectivity of $\mathrm{PODE}_{3-8}$ was increased from 32.06 to $37.65 \%$ with the increase of residence time from 10 to $20 \mathrm{~min}$. The modified catalyst is stable at $20 \mathrm{~min}$ reaction time. The recommended reaction conditions are temperature $343 \mathrm{~K}$, pressure $2 \mathrm{MPa}$ and residence time $20 \mathrm{~min}$.

\section{REFERENCES}

1. G.P. Hagen, US Patent 2003171534 (2003).

2. D.H. Liu, C.F. Yao, J.Q. Zhang, D.Y. Fang and D.S. Chen, Fuel, 90, 1738 (2011)

3. F.E. Celik, T.J. Kim and A.T. Bell, J. Catal., 270, 185 (2010).

4. D. SanFilippo, R. Patrini and M. Marchionna, EP Patent 1422285 (2004).

5. G.P. Hagen and M.J. Spangler, US Patent 6350919 (2002).

6. G.P. Hagen and M.J. Spangler, US Patent 6392102 (2002).

7. G.P. Hagen and M.J. Spangler, US Patent 0171534 (2003).

8. G.P. Hagen and M.J. Spangler, US Patent 6160174 (2000).

9. G.P. Hagen and M.J. Spangler, US Patent 0007089 (2002).

10. J. Burger, M. Siegert, E. Strofer and H. Hasse, Fuel, 89, 3315 (2010).

11. E. Stroefer, H. Hasse and S. Blagov, US Patent 7700809 B2 (2010).

12. R. Patrini and M. Marchionna, EP Patent 1070755 (2001).

13. D.S. Moulton and D.W. Naegeli, US Patent 5746785 (1998).

14. E. Stroefer, H. Hasse and S. Blagov, US Patent7671240 (2010).

15. A. Arteconi, A. Mazzarini and G. Nicola, Water Air Soil Pollut., 221, 405 (2011).

16. Z.P. Mouloungui and V. Rakotondrazafy, R. Valentin and B. Zebib, Ind. Eng. Chem. Res., 48, 6949 (2009).

17. M.C. Annesini, V. Piemonte and L. Turchetti, Asia-Pac. J. Chem. Eng., 7, 510 (2012).

18. T.L. Gunale, V.V. Mahajani, P.K. Wattal and C. Srinivas, Asia-Pac. J. Chem. Eng., 4, 90 (2009). 